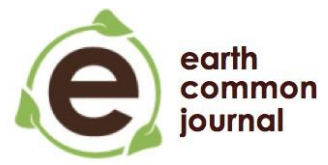

Earth Common Journal Changing Climates: Social, Political, Economic

MacEwan University

Volume 6, Number 1, October 2016

\title{
Review
}

\section{OMEGA: Playing for Change}

A. Rachelle Foss*

\begin{abstract}
Despite all the information we have regarding climate change and the potential perils of continuing on our path of consumption, people are slow to make the necessary changes. Our tendency to live habitually and the dampening effect continuous negative messaging has on people's motivation are affecting society's environmental practices. But one Edmonton based company is working to improve the way we interact with sustainability by making daily "green actions" fun and competitive.
\end{abstract}




\section{Introduction}

An abundance of scientific evidence points to the fact that humanity cannot continue along our current path of environmental destruction. Our atmosphere and air quality are being damaged by fossil fuels (Christoforou, 2004, para. 13) and industrial farming (Bourgeois, 2012) at an alarming rate. Our oceans are permeated with the remnants of our plastic addiction (Foss, 2013, p. 2). And yet, people are still using plastic bags and Styrofoam containers, eating meat at every meal, and buying fuel-guzzling vehicles larger than needed.

Despite this knowledge, the available information "hasn't made an appreciable impact on how people behave with respect to the environment" (S. Gangel, personal communication, July 30, 2016). According to Hansen (1991), "public awareness and concern about the environment developed in the 1960s" (p.2).

So, why is it, that despite everything we know "climate change is still a clear and present danger”? (S. Gangel, personal communication, July 30, 2016).

\section{Changing Behaviours}

The answer to our puzzling lack of action is likely related to the fact that "sustainability is fundamentally about adapting to a new ethic of living on the planet" (Duxbury, Gillette, \& Pepper, 2007, p.2). But, "cognitive psychology suggests that habits, routines and automaticity play a vital role in the cognitive effort required to function effectively" (Jackson, 2005, p. 11). We are essentially struggling to break our habits, despite the risk they pose to our survival.

If all the logical knowledge we have isn't helping us to change our way of existing on the earth because of our habitual nature, can we be motivated in other ways to change our behaviours?

One Edmonton business is using the component of culture to motivate and to transform the way people relate to and practice sustainable living. Sandra Gangel, of Verdigo, explains, "One of our original mottos

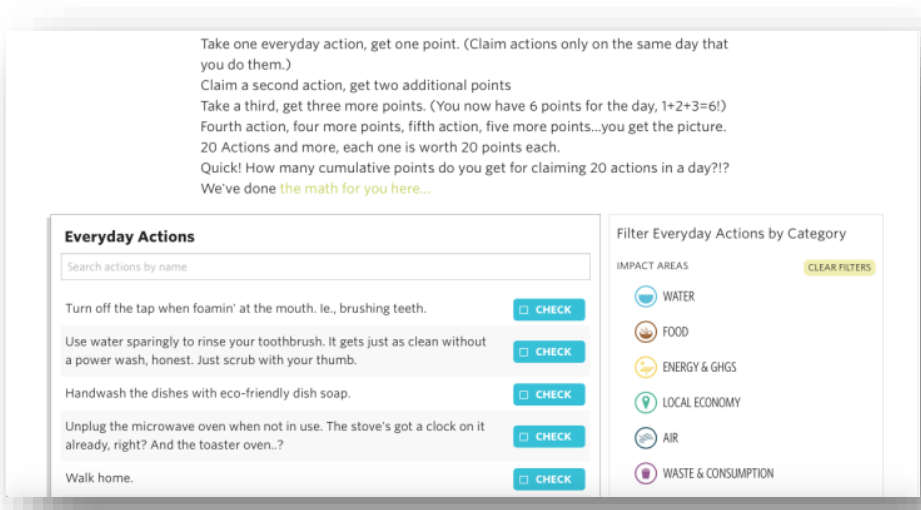

ECJ Volume 6, No. 1, 2016: Changing Climates - Social, Political, Economic 
is, 'It's not the science; it's the social.' We think knowing the facts hasn't been enough to get people to change. But people seem to heed social pressure ('peer pressure') much more readily" (S. Gangel, personal communication, July 30, 2016).

Traditionally, we describe sustainability on a greater scale-countrywide and worldwide levels. But more recently we have started applying these ideas to cities and communities too. This recognition of smaller groups speaks to our increased understanding of the significance of every level of "culture as a component of sustainability" (Duxbury et al., 2007, p. 1).

Gangel explains, "We wanted a way for people to engage with environmentalism through play, in a way that could spread organically" (personal communication, July 30, 2016). Specifically, their vision involves social competition in an online forum.

\section{OMEGA}

"There is already plenty of information out there about what we can do individually, and also a ton of scientific evidence on why we need to do it, oh, decades ago ... [but] life is complicated and sometimes, we can only choose the lesser evil, despite out best intentions" (S. Gangel, personal communication, July 30, 2016). And that is further "complicated by the fact that sustainable development is based on society's always changing worldviews and values" (Duxbury et al., 2005, p. 3).

But Verdigo, a social enterprise comprised of a group of volunteers, all with fulltime careers, has created OMEGA with change in mind. Utilizing the smaller community model, Verdigo is looking to affect change, using fun to motivate people instead of proclamations of doom. Notwithstanding their self-professed laid-back personalities, the passion of those involved with this venture is evident: "OMEGA is our first endeavoura game to get people to continue or introduce 'green' actions in daily life and to stretch the boundaries of their environmentalism" (S. Gangel, personal communication, July 30, 2016).

\section{How it works}

Jackson (2005) explains that, "a degree of automaticity enters our behaviour, making it much more difficult to change" (p.3). Verdigo wants to empower people so they know they can make a difference, no matter how 'green' they currently are. There's always room for improvement . . being greener today than you were yesterday" (S. Gangel, personal communication, July 30, 2016). 
Jackson (2005) points

out, "many

environmentally

significant behaviours

are routine in nature, it

is vital for sustainable

consumption policy to

find ways of addressing

and renegotiating

habitual behaviour" (p.

13). Verdigo noticed a

trend: dire warnings and

\section{\begin{tabular}{ll|l|l|l|l}
\hline & 1 & 3 & 6 & 1 & actions proving Verdigo is walking the walk
\end{tabular}}

DASHBOARD LEADERBOARDS MYPOINTS INVITE YOUR FRIENDS

guilt as a way to motivate people, but wanted to give people a way to participate with environmentalism in a positive and engaging way that could spread organically - through play. Feinberg and Willer (2011) support the idea that reducing the grim messaging that frequently accompanies climate change information could be more effective for promoting public understanding and motivating public action regarding sustainable living. OMEGA is just that - a game of friendly competition. The game is a race for individual communities - cities, towns, businesses, or other institutions - to reach one million environmentally beneficial actions.

According to Jackson's (2005) findings, OMEGA's competitive factor may be part of the key to motivating people to make changes: "human behaviour consists of social, moral and altruistic behaviours as well as simply self- interested ones” (p. 9).

As Jackson (2005) further explains, "effective persuasion relies on observing a number of basic principles . . . including using emotional and imaginative appeal, commitments/loyalty schemes, use of 'retrieval cues' to catalyse the new behavior' (p. 13). It is a common theory within the marketing industry that users respond on an emotional level to purchasing products and making decisions about their behaviour Jackson, 2005, p.3). Looking to meet similar principles and scale the challenge to as large a group of people as possible, they designed the game with three motivators in mind.

1. Keeping up with the Joneses-OMEGA's points competition uses the principle of comparing one's self with one's neighbour as a yardstick for ambition,

2. Smack talk-Verdigo keeps web text light but spirited to arouse affable rivalry and push users to outdo opponents, and

3. Fun-OMEGA appeals to users' imaginations by inviting them to create 
challenges and think of new everyday green actions to outdo fellow competitors.

The overall goal, however-beyond gaining points and winning the race, is to change the way people think about their day. As one member of the Veridgo team explains,

"Say I drove by myself to a meeting yesterday. Well, today, I might take a look at my upcoming schedule and see where I could switch out an in-person meeting for a Skype or Facetime or plain old-fashioned phone call instead. Eventually, I'll be requesting the Skype, etc. right off the bat; it becomes the norm. Not only that, but if I'm explaining to my meeting mates why I prefer video rather than in-person, I may be introducing them to that idea as well as to the game. There's a ripple effect. For some people, that progression would be completely natural. For others, it would be totally new" (S. Gangel, personal communication, July 30, 2016).

This concept is the basis for OMEGA. Whether players are normally conservative in their water use or not, the game puts the idea of using less water, and suggestions for how, in the player's sphere of awareness. According to Clark (2008), "Laying a foundation of education will help grow green roots" (para. 12). It puts people in a position to consider their daily actions, rather than acting solely out of habit.

\section{Changing the world's habits}

Although OMEGA is getting its start in the Edmonton community, the company has a larger vision of bringing their game and sustainable thinking to people across the globe. 'Imagine David Suzuki vs. Bill McKibben . . . Imagine ‘Queen of Green' Lindsay Coulter vs. grist magazine's Umbra Fisk of 'Ask Umbra' fame. That would be a huge amount of points” (S. Gangel, personal communication, July 30, 2016).

This scope may be just what sustainable living needs to grow, because a majority of our daily consumption and energy use is almost invisible, especially to ourselves (Jackson, 2005). But by bringing it to a public forum-social media-

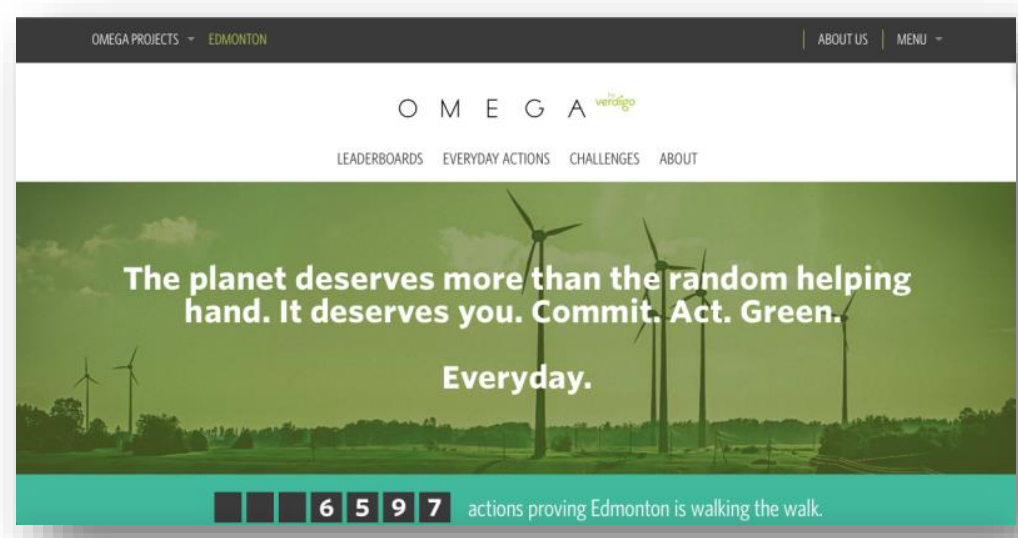


where people can share their successes and failures, sustainable thinking is now in the forefront of our thoughts and not just facts we know in the back of our minds.

We are coming to realize that despite our awareness, for many people there is a gap between knowing information and acting on that information. Today, it is imperative to try to find better ways to inspire and motivate people to act in different and more conscious ways. As the Verdigo team says, "If you're alive, you have an environmental impact; it's unavoidable. What will you choose to do about that?" (S. Gangel, personal communication, July 30, 2016).

* Author: A. Rachelle Foss is a graduate of the Professional Writing and Communication program at MacEwan University, and now works as a freelance writer and editor. She has published with Earth Common Journal since its inangural year, and has been a member of the editorial board since 2012. Direct any professional inquiries to preciseiswrite@gmail.com.

\section{References}

Bourgeois, L. (2012). A Discounted Threat: Environmental Impacts of the Livestock Industry. Earth Common Journal, 2(1), n.p. Retrieved from https://journals.macewan.ca/index.php/earthcommon/index

Christoforou, C. (2004). Air Pollution. In Gale's online encyclopedia (2016). Retrieved from http://www.encyclopedia.com/topic/air_pollution.aspx

Clark, A. (2008, Feb 5). Selling Sustainability. Green Biz. Retrieved from https://www.greenbiz.com/blog/2008/02/05/selling-sustainability

Duxbury, N., Gillette, E., Pepper, K. (2007). Exploring the Cultural Dimensions of Sustainability. Creative City News: Special Edition, 4, 1-4. Retrieved from http://www.creativecity.ca/database/files/library/Creative_City_News_E.pdf

Feinberg, M., Willer, R. (2011, Jan). Apocalypse Soon? Dire Messages Reduce Belief in Global Warming by Contradicting Just World Beliefs. Psychological Science. 22(1), 34-38. doi: 10.1177/0956797610391911

Foss, A. R. (2013). Hoarding plastic waste: Buried alive. Earth Common Journal, 3(1), 70-79. Retrieved from https://journals.macewan.ca/index.php/earthcommon/index 
Hansen, A. (1991). The media and the social construction of the environment. Media, Culture and Society. 13(4), 443-458. doi: 10.1177/016344391013004002

Jackson, T. (2005, Jan). Motivating Sustainable Consumption. Sustainable Development Research Network. Retrieved from http:/ / citeseerx.ist.psu.edu/viewdoc/download?doi=10.1.1.337.433\&rep=rep1\&t ype $=$ pdf 